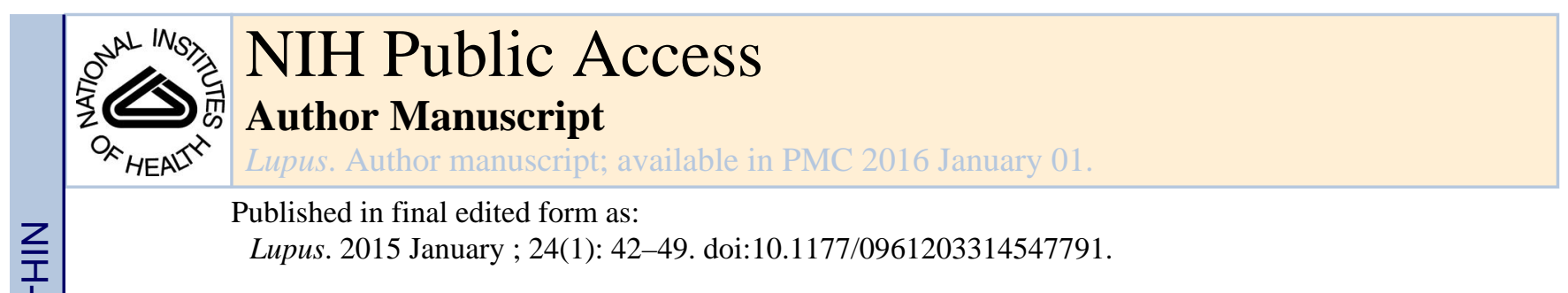

\title{
Anti-C1q Antibodies in Systemic Lupus Erythematosus
}

A full list of authors and affiliations appears at the end of the article.

Abstract

Objective-Anti-C1q has been associated with systemic lupus erythematosus (SLE) and lupus nephritis in previous studies. We studied anti-C1q specificity for SLE (vs. rheumatic disease controls) and the association with SLE manifestations in an international multi-center study.

Methods-Information and blood samples were obtained in a cross-sectional study from patients with SLE $(n=308)$ and other rheumatologic diseases $(n=389)$ from 25 clinical sites ( $84 \%$ female, $68 \%$ Caucasian, $17 \%$ African descent, $8 \%$ Asian, $7 \%$ other). IgG anti-C1q against the collagenlike region was measured by ELISA.

Results-Prevalence of anti-C1q was 28\% (86/308) in patients with SLE and 13\% (49/389) in controls (OR=2.7, 95\% CI: 1.8-4, $\mathrm{p}<0.001)$. Anti-C1q was associated with proteinuria (OR=3.0, 95\% CI: 1.7-5.1, $\mathrm{p}<0.001)$, red cell casts (OR=2.6, 95\% CI: 1.2-5.4, $\mathrm{p}=0.015)$, anti-dsDNA $(\mathrm{OR}=3.4,95 \%$ CI: 1.9-6.1, $\mathrm{p}<0.001)$ and anti-Smith $(\mathrm{OR}=2.8,95 \%$ CI: $1.5-5.0, \mathrm{p}=0.01)$. Anti-C1q was independently associated with renal involvement after adjustment for demographics, ANA, anti-dsDNA and low complement (OR=2.3, 95\% CI: 1.3-4.2, $\mathrm{p}<0.01)$. Simultaneously positive anti-C1q, anti-dsDNA and low complement was strongly associated with renal involvement $(\mathrm{OR}=14.9,95 \%$ CI: 5.8-38.4, $\mathrm{p}<0.01)$.

Conclusions-Anti-C1q was more common in patients with SLE and those of Asian race/ ethnicity. We confirmed a significant association of anti-C1q with renal involvement, independent of demographics and other serologies. Anti-C1q in combination with anti-dsDNA and low complement was the strongest serological association with renal involvement. These data support the usefulness of anti-C1q in SLE, especially in lupus nephritis.

\section{Introduction}

Complement plays a major role in the pathogenesis of systemic lupus erythematosus (SLE) and lupus nephritis. Genetic deficiencies in the early complement components are associated with SLE ${ }^{1,2}$. The strongest association is seen in patients with homozygous C1q deficiency, of whom $88 \%$ developed SLE and $30 \%$ glomerulonephritis, respectively ${ }^{3}$. In vitro, physiologic concentrations of $\mathrm{C} 1 \mathrm{q}$ inhibit interferon alpha production by plasmacytoid dendritic cells stimulated with nucleic acid containing immune complexes ${ }^{4}$, suggesting a regulatory effect of $\mathrm{C} 1 \mathrm{q}$ in response to and clearance of immune complexes. In patients with SLE, levels of C1q were reduced in glomerulonephritis flares ${ }^{5}$. In patients with lupus

Name and address of author responsible for correspondence and reprint requests: Tel: (410) 955-9114 Fax: (410) 614-0498 MPetri@jhmi.edu.

Conflict of Interest Statement

All authors declare no conflict of interest. 
nephritis, the presence of anti-C1q at the time of renal biopsy was associated with worse renal outcome, by the American College of Rheumatology (ACR) renal response criteria ${ }^{6}$, and with renal tubulointerstitial changes ${ }^{7}$. Acquired antibodies against the collagen-like region of $\mathrm{Clq}$ (anti-C1qCLR) were present in the glomerular basement membrane of patients with proliferative lupus nephritis at concentrations more than 50 fold higher per unit $\operatorname{IgG}$ than in the patients' serum, suggesting a role in the pathogenesis of lupus nephritis ${ }^{8}$. $\mathrm{C} 1 \mathrm{q}$ were aggregated within immunoglobulin $\mathrm{G}$ in renal subendothelial deposits in active proliferative lupus nephritis as seen on immunogold electron microscopy, further supporting a pathogenic role of anti-C1q ${ }^{9}$. Patients with active lupus nephritis had a higher prevalence of anti-C1q than those without lupus nephritis, $74 \%$ versus $32 \%(\mathrm{p}<0.0001){ }^{10}$. Anti-C1q increased within 6 months prior to renal involvement in $50 \%$ of patients with SLE ${ }^{11}$ and were associated with the proliferative form of glomerulonephritis ${ }^{1214}$. In another study, an increase in anti-C1q level preceded renal flare by 2.3 months and was more specific for renal flare than increases in anti-dsDNA level ${ }^{15}$. Anti-C1q concentration correlated with activity on the modified SELENA-SLEDAI and the SLICC Renal Activity Score ${ }^{16}$. With immunosuppressive treatment for membranoproliferative lupus nephritis with either cyclophosphamide or azathioprine, anti-C1q disappeared by week 12 and remained undetectable throughout one year of follow-up ${ }^{17}$. As detailed above, evidence suggests that anti-C1q is associated, not only with lupus nephritis, but also with lupus nephritis flares and response to treatment. Therefore anti-C1q might be a candidate for predicting lupus nephritis and monitoring treatment in clinical practice. The purpose of this study was to characterize, in a multinational patient population, the prevalence and clinical associations of anti-C1q in patients with SLE and other rheumatic diseases and to define the association of anti-C1q with renal involvement in patients with SLE.

\section{Patients and methods}

\section{Patients}

We studied anti-C1q specificity for SLE (vs. rheumatic disease controls) and its association with SLE manifestations in an international, multi-center, cross-sectional sample of patients with SLE and other rheumatic diseases, assembled to derive the Systemic Lupus Collaborating Clinics (SLICC) classification criteria for SLE ${ }^{18}$.

\section{Laboratory methods}

Anti-C1q determination was performed at the laboratory of Lennart Truedsson MD, $\mathrm{PhD}$ (Department of Microbiology and Clinical Immunology, Lund University Hospital, Sweden). An enzyme-linked immunosorbent assay (ELISA) with purified collagenous C1q fragments in the solid phase was used for detection of anti-C1q IgG in all serum samples obtained in the beginning of the study. The assay was previously described ${ }^{19}$ and it is well documented that autoantibodies against C1q in SLE target the collagenous portion of the molecule 20,21. Use of purified C1q collagenous fragments as antigen in the ELISA prevented non-specific interactions. The reference interval was defined as $<16 \mathrm{AU} / \mathrm{L}$ based on analysis of anti-C1q IgG in 96 healthy blood donors ${ }^{22}$. 
Laboratory determinations were performed at the Rheumatology Diagnostic Laboratory (Los Angeles, CA) for anti-dsDNA by enzyme-linked immunosorbent assay (ELISA), Crithidia assay and Farr assay, and for anti-Smith antibody and complement $\mathrm{C} 3$ and $\mathrm{C} 4$ levels. Another set of blood samples were tested for antiphospholipid antibodies (lupus anticoagulant, and ELISA for $\operatorname{IgG}, \operatorname{IgM}$, and $\operatorname{IgA}$ isotypes of anticardiolipin antibodies and anti- $\beta 2$-glycoprotein I antibodies) at the laboratory of Joan Merrill, MD (Oklahoma Medical Research Foundation).

\section{Statistical methods}

Statistical analyses were carried out using SAS® (SAS® 9.2, SAS Institute Inc., Cary, North Carolina, USA) and Stata statistical software (Stata 12, StataCorp LP, College Station, Texas, USA). Patients with SLE and controls with rheumatic disease were compared with respect to demographic characteristics, clinical manifestations, and serologic results using Chi-square tests; $\mathrm{p}$-values for Chi-square tests were adjusted for age and ethnicity as specified in the tables. A p-value $\leq 0.05$ was considered statistically significant. In patients with SLE, we calculated odds ratios of renal involvement, by the SLICC classification criteria (urine protein to creatinine ratio or 24-hour urine protein representing 500mg/24 hours or red blood cell casts) ${ }^{23}$, using multiple logistic regression on demographic and serologic characteristics. The first model adjusted for demographics (age, ethnicity, gender) and individual antibodies (ANA, anti-dsDNA, low complement $\mathrm{C} 3$ and/or C4 and anti-C1q). The second model adjusted for demographics and serologic patterns for anti-C1q, antidsDNA and low complement C3 and/or C4.

The study was approved by institutional review boards at all institutions involved, and all participants provided written informed consent.

\section{Results}

Clinical information and blood samples were obtained from 308 patients with SLE ( mean age (SD) 34 (13) years, 89\% female, 63\% Caucasian, 22\% African descent, 12\% Asian, 3\% other) and 389 patients with other rheumatologic diseases (mean age (SD) 43 (15) years, 80\% female, $73 \%$ Caucasian, $13 \%$ African descent, 5\% Asian, 9\% other) from 25 clinical sites. SLICC renal involvement was present in 33\% of patients with SLE and $4 \%$ of controls. Of 308 patients with SLE, 72 (23\%) had biopsy confirmed lupus nephritis (and none of the controls).

\section{Anti-C1q prevalence by diagnosis}

The prevalence of anti-C1q was 28\% (86/308) in patients with SLE and 13\% (49/389) in controls with other rheumatologic disorders (OR=2.7, 95\% CI 1.8-4.0, $\mathrm{p}<0.001)$. The frequency of anti-C1q in rheumatic disease controls was: $26 \%$ in scleroderma, $19 \%$ in rheumatoid arthritis, $15 \%$ in undifferentiated connective tissue disease, $15 \%$ in chronic cutaneous lupus, $14 \%$ in Sjögren syndrome, $8 \%$ in fibromyalgia, $7 \%$ in antiphospholipid antibody syndrome, $6 \%$ in dermatomyositis, and $5 \%$ in vasculitis. 


\section{Anti-C1q and demographic characteristics in patients with SLE}

Anti-C1q was more common in Asians ( $\mathrm{n}=37,40.5 \%)$ than in Caucasians ( $\mathrm{n}=192,27.6 \%)$ or patients of African descent ( $\mathrm{n}=69,21.7 \%$ ), but these differences were not statistically significant. Anti-C1q was more common in younger individuals with SLE, using an age cutoff of 30 years $(35.5 \%$ versus $23 \%, \mathrm{p}=0.02)$ (Table 1$)$.

\section{Anti-C1q and clinical SLE manifestations}

Sensitivity of anti-C1q for a classification of SLE was $28 \%$ and specificity was $87 \%$. In an age adjusted analysis we assessed the clinical features of SLE associated with anti-C1q antibodies. Patients with anti-C1q were significantly more likely to have proteinuria $(\mathrm{OR}=3.0,95 \% \mathrm{CI} 1.7-5.1, \mathrm{p}<0.001)$ and urinary red cell casts $(\mathrm{OR}=2.6,95 \% \mathrm{CI} 1.2-5.4$, $\mathrm{p}=0.015)$. There was a trend towards an association with psychosis $(\mathrm{OR}=9.5,95 \% \mathrm{CI} 0.9-$ $98.5, \mathrm{p}=0.06$ ). No significant associations were seen with arthritis, cutaneous lupus or hematologic manifestations (Table 2).

\section{Anti-C1q and serologic SLE manifestations}

In patients with SLE positive for anti-C1q (compared to patients negative for anti-C1q), there were positive associations with anti-dsDNA (OR=3.4, 95\% CI 1.9-6.1, $<<0.001)$ and anti-Smith $(\mathrm{OR}=2.8,95 \%$ CI $1.5-5.0, \mathrm{p}=0.01)$ and no association with antiphospholipid antibodies after adjustment for age (Table 2).

\section{Anti-C1q and lupus nephritis}

Sensitivity of anti-C1q for SLE renal involvement was $41 \%$ and specificity was $85 \%$. AntiC1q prevalence in patients with SLE with, versus without ACR renal disorder (persistent proteinuria $>0.5 \mathrm{~g} / 24 \mathrm{~h}$ or proteinuria $>3+$, or red blood cell casts) was $45.5 \%$ compared to $19.3 \%$, respectively $(\mathrm{OR}=3.2,95 \%$ CI $1.8-5.6, \mathrm{p}<0.001)$. Additional serologic associations observed for ACR renal disorder were with anti-dsDNA (OR=4.7, 95\% CI 2.5 - 8.6, $\mathrm{p}<0.001)$, low complement ( $\mathrm{OR}=2.8,95 \%$ CI 1.5 - 4.9, $\mathrm{p}=0.001)$ and anti-Smith $(\mathrm{OR}=1.9$, 95\% CI 1.1 -3.6, $\mathrm{p}=0.03$ ), after adjustment for age and ethnicity (Table 3).

The first logistic regression model was applied to all patients with SLE $(n=308)$ to estimate the independent contribution of demographic characteristics and serologies to odds of SLICC renal involvement $(\mathrm{n}=101)$. Odds of SLICC renal involvement were two times lower in patients above age 30 than below age $30(\mathrm{OR}=0.4,95 \% \mathrm{CI} 0.3-0.8, \mathrm{p}=0.005)$ and, independently of age, three times lower in Caucasians compared to African-Americans $(\mathrm{OR}=0.3,95 \% \mathrm{CI} 0.1-0.6, \mathrm{p}<0.001)$, after adjustment for gender and serologies (Table 4).

Odds of SLICC renal involvement in the presence of anti-dsDNA were 4 times higher than in the absence of anti-dsDNA, after adjustment for age, ethnicity, gender and serologies (OR $=4.1,95 \%$ CI $2.1-7.9, \mathrm{p}<0.001)$. In the same model, for anti-C1q positive, odds of SLICC renal involvement were independently 2.3 times higher than in the absence of anti-C1q $(\mathrm{OR}=2.3,95 \% \mathrm{CI} 1.3-4.2, \mathrm{p}=0.007)$ (Table 4). Low complement $\mathrm{C} 3$ and/or C4, compared to normal, was associated with double the odds of SLICC renal involvement, a finding that was not statistically significant after adjustment for anti-dsDNA and anti-C1q $(\mathrm{OR}=1.9$, 95\% CI $1.0-3.6, \mathrm{p}=0.06)$. 
The second logistic regression model estimated odds of SLICC renal involvement using possible combinations of serology results for anti-dsDNA, anti-C1q and low complement and adjusted for age, ethnicity and gender. By patterns of positivity for anti-C1q, antidsDNA and low complement, odds of SLICC renal involvement were 15 times higher for patients with all three serologies positive compared to all negative ( $\mathrm{OR}=14.9,95 \%$ CI 5.8 $38.4, \mathrm{p}<0.001)$. In the same model, combinations of simultaneously positive anti-dsDNA and low complement, and simultaneously positive anti-dsDNA and anti-C1q were associated with 5 times and 6 times increase in odds of SLICC renal involvement than all three serologies negative, respectively (OR=5.2 95\% CI $2.1-13.1, \mathrm{p}<0.001$ and $\mathrm{OR}=5.795 \% \mathrm{CI}$ $1.2-28.3, \mathrm{p}=0.03)$ (Table 5).

\section{Discussion}

Anti-C1q has been associated with SLE and SLE nephritis in previous studies 10, 12, 14, 24-28. We confirmed this association in the SLICC international patient population, in which we studied 308 patients with SLE and 389 controls with other rheumatologic diseases. We also showed, for the first time, the association of anti-C1q with lupus renal involvement by SLICC classification criteria.

The presence of anti-C1q antibodies in other autoimmune diseases, as we have found, and even in healthy individuals (4\% to $6.4 \%$ ), has been previously reported ${ }^{2129}$. Patients with scleroderma were anti-C1q positive in a higher proportion in our study, 26\%, than observed in other studies, $5.5 \%{ }^{24}$. None of these patients had renal involvement. Patients with rheumatoid arthritis were anti-C1q positive in a higher proportion in our study, 19\%, than observed in other studies, $5 \%{ }^{30}$. However, a review by Seelen MA et al. reported anti-C1q prevalence of $77 \%$ in rheumatoid vasculitis ${ }^{31}$. Patients with vasculitis were less often positive in the population we studied, $5 \%$, versus $1235 \%$ in other studies ${ }^{29}$. We did not collect information on type of vasculitis and ANCA status. Anti-C1q has not been previously described in dermatomyositis in which we found a prevalence of anti-C1q of $6 \%$ (based on 55 patients). Anti-C1q were more common in Asians (40.5\%) than in Caucasians (27.6\%) and patients of African descent (21.7\%), but these differences were not statistically significant, consistent with previous studies ${ }^{32}$. We found that younger individuals with SLE were more likely to be anti-C1q positive than older individuals, using an age cutoff of 30 years. Siegert et al., similarly, found a higher prevalence of IgG anti-C1q antibodies in younger individuals with SLE compared to random selected controls (highest titer and highest prevalence below age 30); in patients with SLE anti-C1q prevalence decreased with age while in random controls the opposite was true ${ }^{33}$. Anti-C1q antibody prevalence in patients with SLE with ACR renal involvement was $45.5 \%$ in our study. Braun et al. found a prevalence of $61.7 \%$ in biopsy proven lupus nephritis cases ${ }^{29}$ and Wener et al., $48 \%{ }^{21}$. The strongest clinical association we observed for anti-C1q was with proteinuria, consistent with published data $12,14,16,27,34$. Our study was undertaken in patients with SLE from a multicenter, multiethnic patient population and an equal number of patients with other rheumatic diseases (controls), in which complete clinical, serologic and candidate criteria variables were assessed for the purpose of deriving SLE classification rules. We did not have flare data, treatment data, or repeat anti-C1q antibody levels, because of the crosssectional nature of this study. Therefore, any temporal relationship of anti-C1q antibody 
levels to flares of lupus nephritis or change in treatment could not be assessed. Others noted that anti-C1q antibody levels increased prior to flares of lupus nephritis and disappeared with immunosuppressive treatment ${ }^{111526}$. Moroni G. et al. showed an association with active lupus nephritis for anti-C1q and low complement ${ }^{14}$. Yang XW et al. showed concomitant presence of anti-C1q and anti-dsDNA was associated with higher lupus nephritis activity and poor renal outcome compared to only one or none of these antibodies ${ }^{28}$. Anti-C1q in our study had the highest prevalence in patients with SLE with ACR renal involvement and was strongly associated with anti-dsDNA and low complement. It was the second highest antibody associated with a diagnosis of ACR renal involvement, after anti-dsDNA. By the SLICC classification criteria, age above 30 years and being Caucasian were protective from SLICC renal involvement: these characteristics were independently associated with decreased odds of renal involvement in patients with SLE by two and three times, respectively, which is consistent with the literature on the subject. Independently of each other, anti-dsDNA (versus negative) was associated with 4 times higher odds of SLICC renal involvement and anti-C1q (versus negative) was associated with two times higher odds of SLICC renal involvement, after adjustment for age, ethnicity, gender and low complement. In patients with SLE, odds of SLICC renal involvement were highest in the presence of simultaneously positive anti-dsDNA, anti-C1q and low complement (15 times higher than all negative). Increases in odds of SLICC renal involvement with concomitantly positive anti-dsDNA and low complement were similar to concomitantly positive anti-dsDNA and anti-C1q. As seen in the logistic regression models, the three serologies (anti-C1q, anti-dsDNA, low complement) had a multiplicative relationship in increasing the odds of SLICC renal involvement, after adjustment for demographics.

Many studies of anti-C1q antibodies are performed with methods using whole C1q molecules as antigen and a buffer with high ionic strength to prevent nonspecific interaction between the globular heads of $\mathrm{Clq}$ and antibodies. In this study the purified collagenous fragment was used as antigen in the ELISA and the nonspecific interactions were thereby avoided ${ }^{19}$. Comparisons between the method used here and the high salt buffer method in 100 patients with high and low disease activity have given very similar results (Truedsson et al., pers communication). The reason anti-C1q was eliminated, at the end of the derivation phase of the SLICC classification criteria for SLE, was mainly because of a lack of a high quality, standardized, less laborious assay. As new laboratory techniques develop and further uses of anti-C1q determinations become important for clinical care and disease prognosis, anti-C1q can be reconsidered for inclusion in classification criteria and in the clinical management of SLE.

\section{Authors}

ANA-MARIA ORBAI, M.D., M.H.S. ${ }^{1}$, LENNART TRUEDSSON, M.D., Ph.D. ${ }^{2}$, GUNNAR STURFELT, M.D., Ph.D. ${ }^{3}$, OLA NIVED, M.D. ${ }^{3}$, HONG FANG, M.D., M.S. 1, GRACIELA S. ALARCÓN, M.D., M.P.H. ${ }^{4}$, CAROLINE GORDON, M.D., F.R.C.P. 5, JOAN T. MERRILL, M.D. ${ }^{6}$, PAUL R. FORTIN, M.D., M.P.H. ${ }^{7}$, IAN N. BRUCE, M.D. ${ }^{8}$, DAVID A. ISENBERG, M.D. ${ }^{9}$, DANIEL J. WALLACE, M.D. ${ }^{10}$, ROSALIND RAMSEY-GOLDMAN, M.D., Dr.PH ${ }^{11}$, SANG-CHEOL BAE, M.D., Ph.D., M.P.H. ${ }^{12}$, 
JOHN G. HANLY, M.D. ${ }^{13}$, JORGE SANCHEZ-GUERRERO, M.D. ${ }^{14}$, ANN E. CLARKE, M.D., M.Sc. ${ }^{15}$, CYNTHIA B. ARANOW, M.D. ${ }^{16}$, SUSAN MANZI, M.D., M.P.H. ${ }^{17}$, MURRAY B. UROWITZ, M.D. ${ }^{18}$, DAFNA D. GLADMAN, M.D. ${ }^{18}$, KENNETH C. KALUNIAN, M.D., M.P.H. ${ }^{19}$, MELISSA I. COSTNER, M.D. ${ }^{20}$, VICTORIA P. WERTH, M.D. ${ }^{21}$, ASAD ZOMA, M.B., Ch.B. ${ }^{22}$, SASHA BERNATSKY, M.D., Ph.D. ${ }^{15}$, GUILLERMO RUIZ-IRASTORZA, M.D., Ph.D. ${ }^{23}$, MUNTHER A. KHAMASHTA, M.D., Ph.D. ${ }^{24}$, SOREN JACOBSEN, M.D., D.M.Sci. ${ }^{25}$, JILL P. BUYON, M.D. ${ }^{26}$, PETER MADDISON, M.D. ${ }^{27}$, MARY ANNE DOOLEY, M.D., M.P.H. ${ }^{28}$, RONALD F. VAN VOLLENHOVEN, M.D., Ph.D. ${ }^{29}$, ELLEN GINZLER, M.D., M.P.H. ${ }^{30}$, THOMAS STOLL, M.D. ${ }^{31}$, CHRISTINE PESCHKEN, M.D., M.Sc. ${ }^{32}$, JOSEPH L. JORIZZO, M.D. ${ }^{33}$, JEFFREY P. CALLEN, M.D. ${ }^{34}$, S. SAM LIM, M.D., M.P.H. ${ }^{35}$, BARRI J. FESSLER, M.D., M.S.P.H. ${ }^{4}$, MURAT INANC, M.D. ${ }^{36}$, DIANE L. KAMEN, M.D., M.S.C.R ${ }^{37}$, ANISUR RAHMAN, M.D., Ph.D. ${ }^{9}$, KRISTJAN STEINSSON, M.D., Ph.D. ${ }^{38}$, ANDREW G. FRANKS JR., M.D. ${ }^{26}$, LISA SIGLER, M.A. ${ }^{1}$, SUHAIL HAMEED, M.D. ${ }^{1}$, NEENA PHAM, B.A. ${ }^{1}$, ROBIN BREY, M.D. ${ }^{39}$, MICHAEL H. WEISMAN, M.D. ${ }^{40}$, GERALD MCGWIN JR., Ph.D. M.S. ${ }^{4}$, LAURENCE S. MAGDER, Ph.D., M.P.H. ${ }^{41}$, and MICHELLE PETRI, M.D., M.P.H. ${ }^{1}$

\section{Affiliations}

${ }^{1}$ Division of Rheumatology Johns Hopkins University School of Medicine $1830 \mathrm{E}$. Monument Street, Suite 7500 Baltimore, MD 21205, USA 2Dept of Laboratory Medicine, Section of Microbiology, Immunology and Glycobiology, Lund University, S-22100 Lund, Sweden ${ }^{3}$ Department of Rheumatology Skåne University Hospital S-22185 Lund, SWEDEN ${ }^{4}$ Department of Medicine, Division of Clinical Immunology and Rheumatology University of Alabama at Birmingham Birmingham, AL 35294 USA ${ }^{5}$ Rheumatology Research Group School of Immunity and Infection College of Medical and Dental Sciences University of Birmingham Birmingham, B15 2TT, UK ${ }^{6}$ Department of Clinical Pharmacology Oklahoma Medical Research Foundation Oklahoma City, OK 73104 USA ${ }^{7}$ Division of Rheumatology, Department of Medicine, Centre Hospitalier Universitaire (CHU) de Québec Axe Maladies Infectieuses et Immunitaires, CRCHU de Québec, Université Laval, Quebec City, Quebec, Canada ${ }^{8}$ Arthritis Research UK Epidemiology Unit, School of Translational Medicine, Manchester Academic Health Science Centre, The University of Manchester, Oxford Road, Manchester, UK M13 9PT ${ }^{9}$ Centre for Rheumatology Research Division of Medicine London W1T 4JF, UK ${ }^{10}$ Cedars-Sinai Medical Center David Geffen School of Medicine University of California Los Angeles, California 90048,USA ${ }^{11}$ Northwestern University Feinberg School of Medicine Chicago, Ilinois 60611 USA ${ }^{12}$ Department of Rheumatology Hanyang University Hospital for Rheumatic Diseases Seoul 133-792, KOREA ${ }^{13}$ Division of Rheumatology, Departments of Medicine and Pathology Capital Health and Dalhousie University Halifax, Nova Scotia, CANADA B3H 4K4 ${ }^{14}$ Mount Sinai Hospital and University Health Network, Toronto, Ontario, Canada ${ }^{15}$ Divisions of Clinical Epidemiology and Rheumatology McGill University Health Centre Montreal, Quebec, CANADA H3A $1 A 1{ }^{16}$ Feinstein Institute for Medical Research Manhasset New York 11030, USA ${ }^{17}$ Department of Medicine, Division of Rheumatology Allegheny Singer Research 
Institute Allegheny General Hospital Pittsburgh Pennsylvania, $15212{ }^{18}$ Toronto Western Hospital Toronto, Ontario, CANADA M5T 2S8 ${ }^{19}$ Division of Rheumatology, Allergy and Immunology UCSD School of Medicine LaJolla, California 92037 USA ${ }^{20}$ North Dallas Dermatology Associates Dallas, Texas 75231, USA ${ }^{21}$ Philadelphia VA Medical Center and University of Pennsylvania, Philadelphia Pennsylvania ${ }^{22}$ Lanarkshire Centre for Rheumatology and Hairmyres Hospital East Kilbride, UK ${ }^{23}$ Autoimmune Diseases Research Unit Hospital Universitario Cruces Universidad del Pais Vasco Barakaldo, Spain ${ }^{24}$ Rayne Institute and St. Thomas' Hospital London, UK ${ }^{25}$ Rigshospitalet, Copenhagen University Hospital Copenhagen, Denmark ${ }^{26}$ New York University New York, New York ${ }^{27}$ Ysbyty Gwynedd Bangor, UK ${ }^{28}$ University of North Carolina Chapel Hill NC ${ }^{29}$ Karolinska University Hospital Stockholm, Sweden ${ }^{30}$ State University of New York Downstate Medical Center, Brooklyn, New York ${ }^{31}$ Kantonsspital Schaffhausen, Schaffhausen, Switzerland ${ }^{32}$ University of Manitoba Winnipeg, Manitoba, Canada ${ }^{33}$ Wake Forest University Winston-Salem NC ${ }^{34}$ University of Louisville, Louisville, Kentucky ${ }^{35}$ Emory University, Atlanta, Georgia $30322{ }^{36}$ Division of Rheumatology, Department of Internal Medicine Istanbul Medical faculty, Istanbul University Istanbul, Turkey ${ }^{37}$ Medical University of South Carolina, Charleston, South Carolina ${ }^{38}$ Landspitali University Hospital Reykjavik, Iceland ${ }^{39}$ University of Texas Health Science Center San Antonio, Texas ${ }^{40}$ Cedars-Sinai Medical Center Los Angeles, California 90048 ${ }^{41}$ Department of Epidemiology and Public Health University of Maryland Baltimore, MD 21201, USA

\section{Acknowledgement}

We thank Mrs. Joyce Kosmas, Johns Hopkins Arthritis Center, for her help with manuscript submission.

Funding Acknowledgement

The sources of support in the form of grants or industrial support:

Supported by NIAMS and Lupus Foundation of America.

Also supported by an unrestricted Research Grant from Human Genome Sciences.

Dr. Ana-Maria Orbai was supported by NIH grant T32 AR048522.

Dr. Gunnar Sturfelt and Dr. Lennart Truedsson were supported by grants from Greta and Johan Kock's Foundation, King Gustaf V's 80th Birthday Foundation and the Swedish Rheumatism Association.

Dr. Caroline Gordon is supported by Lupus UK.

Dr. Paul R. Fortin is supported by a Canada Research Chair on Systemic Autoimmune Rheumatic Diseases.

Dr. David A. Isenberg and Dr. Anisur Rahman are supported by the National Institute for Health Research University College London Hospitals Biomedical Research Centre.

Dr. Sang-Cheol Bae was supported by the Korea Healthcare Technology R \& D Project, Ministry for Health and Welfare, Republic of Korea (A120404). 


\section{References}

1. Botto M, Walport MJ. C1q, autoimmunity and apoptosis. Immunobiology. 2002; 205:395-406. [PubMed: 12396002]

2. Sturfelt G, Truedsson L. Complement in the immunopathogenesis of rheumatic disease. Nature reviews Rheumatology. 2012; 8:458-68.

3. Schejbel L, Skattum L, Hagelberg S, et al. Molecular basis of hereditary C1q deficiency--revisited: identification of several novel disease-causing mutations. Genes and immunity. 2011; 12:626-34. [PubMed: 21654842]

4. Lood C, Gullstrand B, Truedsson L, et al. C1q inhibits immune complex-induced interferon-alpha production in plasmacytoid dendritic cells: a novel link between $\mathrm{C} 1 \mathrm{q}$ deficiency and systemic lupus erythematosus pathogenesis. Arthritis and rheumatism. 2009; 60:3081-90. [PubMed: 19790049]

5. Sturfelt G, Johnson U, Sjoholm AG. Sequential studies of complement activation in systemic lupus erythematosus. Scandinavian journal of rheumatology. 1985; 14:184-96. [PubMed: 4001891]

6. Renal Disease Subcommittee of the American College of Rheumatology Ad Hoc Committee on Systemic Lupus Erythematosus Response C. The American College of Rheumatology response criteria for proliferative and membranous renal disease in systemic lupus erythematosus clinical trials. Arthritis and rheumatism. 2006; 54:421-32. [PubMed: 16453282]

7. Nived OH, Alm CS, Jonsen P, Sturfelt A, Bengtsson G. A. An observational study of outcome in SLE patients with biopsy-verified glomerulonephritis between 1986 and 2004 in a defined area in Southern Sweden:the clinical utility of the ACR renal response criteria and predictors for renal outcome. Scan J Rheumatol. 2013; 00:1-7.

8. Mannik M, Wener MH. Deposition of antibodies to the collagen-like region of C1q in renal glomeruli of patients with proliferative lupus glomerulonephritis. Arthritis and rheumatism. 1997; 40:1504-11. [PubMed: 9259432]

9. Sjowall C, Olin AI, Skogh T, et al. Co-localization of C-reactive protein, immunoglobulin G and complement in renal subendothelial immune deposits of proliferative lupus nephritis detected using immunogold electron microscopy. Arthritis and rheumatism. 2012; 64:S285.

10. Marto N, Bertolaccini ML, Calabuig E, Hughes GR, Khamashta MA. Anti-C1q antibodies in nephritis: correlation between titres and renal disease activity and positive predictive value in systemic lupus erythematosus. Annals of the rheumatic diseases. 2005; 64:444-8. [PubMed: 15286009]

11. Siegert CE, Daha MR, Tseng CM, Coremans IE, van Es LA, Breedveld FC. Predictive value of IgG autoantibodies against $\mathrm{C} 1 \mathrm{q}$ for nephritis in systemic lupus erythematosus. Annals of the rheumatic diseases. 1993; 52:851-6. [PubMed: 8311534]

12. Trendelenburg M, Lopez-Trascasa M, Potlukova E, et al. High prevalence of anti-C1q antibodies in biopsy-proven active lupus nephritis. Nephrology, dialysis, transplantation : official publication of the European Dialysis and Transplant Association - European Renal Association. 2006; 21:3115-21.

13. Fang QY, Yu F, Tan Y, et al. Anti-C1q antibodies and IgG subclass distribution in sera from Chinese patients with lupus nephritis. Nephrology, dialysis, transplantation : official publication of the European Dialysis and Transplant Association - European Renal Association. 2009; 24:172-8.

14. Moroni G, Radice A, Giammarresi G, et al. Are laboratory tests useful for monitoring the activity of lupus nephritis? A 6-year prospective study in a cohort of 228 patients with lupus nephritis. Annals of the rheumatic diseases. 2009; 68:234-7. [PubMed: 18718989]

15. Coremans IE, Spronk PE, Bootsma H, et al. Changes in antibodies to C1q predict renal relapses in systemic lupus erythematosus. American journal of kidney diseases : the official journal of the National Kidney Foundation. 1995; 26:595-601. [PubMed: 7573013]

16. Akhter E, Burlingame RW, Seaman AL, Magder L, Petri M. Anti-C1q antibodies have higher correlation with flares of lupus nephritis than other serum markers. Lupus. 2011; 20:1267-74. [PubMed: 21813587]

17. Grootscholten C, Dieker JW, McGrath FD, et al. A prospective study of anti-chromatin and antiC1q autoantibodies in patients with proliferative lupus nephritis treated with cyclophosphamide 
pulses or azathioprine/methylprednisolone. Annals of the rheumatic diseases. 2007; 66:693-6. [PubMed: 17135217]

18. Petri M, Orbai AM, Alarcon GS, et al. Derivation and validation of the Systemic Lupus International Collaborating Clinics classification criteria for systemic lupus erythematosus. Arthritis and rheumatism. 2012; 64:2677-86. [PubMed: 22553077]

19. Martensson U, Sjoholm AG, Sturfelt G, Truedsson L, Laurell AB. Western blot analysis of human $\mathrm{IgG}$ reactive with the collagenous portion of $\mathrm{C} 1 \mathrm{q}$ : evidence of distinct binding specificities. Scandinavian journal of immunology. 1992; 35:735-44. [PubMed: 1604245]

20. Antes U, Heinz HP, Loos M. Evidence for the presence of autoantibodies to the collagen-like portion of $\mathrm{C} 1 \mathrm{q}$ in systemic lupus erythematosus. Arthritis and rheumatism. 1988; 31:457-64. [PubMed: 3258749]

21. Wener MH, Uwatoko S, Mannik M. Antibodies to the collagen-like region of C1q in sera of patients with autoimmune rheumatic diseases. Arthritis and rheumatism. 1989; 32:544-51. [PubMed: 2785797]

22. Jonsson G, Sjoholm AG, Truedsson L, Bengtsson AA, Braconier JH, Sturfelt G. Rheumatological manifestations, organ damage and autoimmunity in hereditary $\mathrm{C} 2$ deficiency. Rheumatology (Oxford, England). 2007; 46:1133-9.

23. Petri M, Orbai AM, Alarcon GS, et al. Derivation and validation of systemic lupus international collaborating clinics classification criteria for systemic lupus erythematosus. Arthritis and rheumatism. 2012

24. Horvath L, Czirjak L, Fekete B, et al. Levels of antibodies against C1q and $60 \mathrm{kDa}$ family of heat shock proteins in the sera of patients with various autoimmune diseases. Immunology letters. 2001; 75:103-9. [PubMed: 11137133]

25. Mannik M, Merrill CE, Stamps LD, Wener MH. Multiple autoantibodies form the glomerular immune deposits in patients with systemic lupus erythematosus. The Journal of rheumatology. 2003; 30:1495-504. [PubMed: 12858447]

26. Sinico RA, Radice A, Ikehata M, et al. Anti-C1q autoantibodies in lupus nephritis: prevalence and clinical significance. Annals of the New York Academy of Sciences. 2005; 1050:193-200. [PubMed: 16014534]

27. Zhang CQ, Ren L, Gao F, Mu FY, You YQ, Liu YH. Anti-C1q antibodies are associated with systemic lupus erythematosus disease activity and lupus nephritis in northeast of China. Clinical rheumatology. 2011; 30:967-73. [PubMed: 21340499]

28. Yang XW, Tan Y, Yu F, Zhao MH. Combination of anti-C1q and anti-dsDNA antibodies is associated with higher renal disease activity and predicts renal prognosis of patients with lupus nephritis. Nephrology, dialysis, transplantation : official publication of the European Dialysis and Transplant Association - European Renal Association. 2012; 27:3552-9.

29. Braun A, Sis J, Max R, et al. Anti-chromatin and anti-C1q antibodies in systemic lupus erythematosus compared to other systemic autoimmune diseases. Scandinavian journal of rheumatology. 2007; 36:291-8. [PubMed: 17763207]

30. Trad B, Ben Hassine H, Khalifa M, et al. Anti-C1q antibodies and systemic lupus erythematosus in the Tunisian population. Pathologie-biologie. 2013; 61:113-6. [PubMed: 23399411]

31. Seelen MA, Trouw LA, Daha MR. Diagnostic and prognostic significance of anti-C1q antibodies in systemic lupus erythematosus. Current opinion in nephrology and hypertension. 2003; 12:61924. [PubMed: 14564199]

32. Heinlen LD, McClain MT, Merrill J, et al. Clinical criteria for systemic lupus erythematosus precede diagnosis, and associated autoantibodies are present before clinical symptoms. Arthritis and rheumatism. 2007; 56:2344-51. [PubMed: 17599763]

33. Siegert CE, Daha MR, Swaak AJ, van der Voort EA, Breedveld FC. The relationship between serum titers of autoantibodies to $\mathrm{C} 1 \mathrm{q}$ and age in the general population and in patients with systemic lupus erythematosus. Clinical immunology and immunopathology. 1993; 67:204-9. [PubMed: 8500268]

34. Balanescu E, Tanasescu C, Balanescu P, et al. Anti C1q antibodies in cutaneous lupus erythematosus. Romanian journal of internal medicine $=$ Revue roumaine de medecine interne . 2010; 48:159-63. [PubMed: 21428180] 


\section{Table 1}

Association between Demographic Characteristics and Anti-C1q in SLE: Percentage of Patients with AntiC1q, by Demographic Variables

\begin{tabular}{lll}
\hline Demographics & Percentage for Anti-C1q & p-value \\
\hline Ethnicity & & \\
African Descent & 21.7 & 0.15 \\
Caucasian & 27.6 & \\
Asian & 40.5 & \\
Other & 30.0 & \\
Gender & & 0.25 \\
Female & 26.9 & \\
Male & 36.4 & 0.01 \\
Age (years) & & \\
30 & 35.5 & \\
$>30$ & 23.0 & \\
\hline
\end{tabular}




\section{Table 2}

Association between ACR Criteria and Anti-Clq in SLE: Percentage of Patients with Various Clinical Conditions, by Anti-C1q Status

\begin{tabular}{lrrrrr}
\hline ACR Criteria & Anti-C1q Positive (\%) & Anti-C1q Negative (\%) & p-value & Odds Ratio (95\% CI) & Adjusted p-value for Age \\
\hline Malar Rash & 47.7 & 46.9 & 0.90 & $0.9(0.5,1.5)$ & 0.69 \\
Discoid Rash & 19.8 & 19.4 & 0.94 & $1.1(0.6,2.1)$ & 0.71 \\
Photosensitivity & 53.5 & 53.2 & 0.96 & $1.0(0.6,1.7)$ & 1.00 \\
Oral Ulcers & 38.4 & 46.4 & 0.20 & $0.7(0.4,1.1)$ & 0.14 \\
Arthritis & 64.0 & 65.8 & 0.76 & $0.9(0.5,1.5)$ & 0.70 \\
Serositis & 37.2 & 34.7 & 0.68 & $1.1(0.6,1.8)$ & 0.84 \\
Pleurisy & 31.4 & 28.4 & 0.60 & $1.1(0.6,1.9)$ & 0.74 \\
Pericarditis & 14.0 & 12.2 & 0.67 & $1.2(0.6,2.5)$ & 0.66 \\
Proteinuria & 50.0 & 22.5 & $<0.01$ & $3.0(1.7,5.1)$ & $<\mathbf{0 . 0 1}$ \\
Red cell casts & 18.6 & 7.2 & $<0.01$ & $2.6(1.2,5.4)$ & $\mathbf{0 . 0 2}$ \\
Seizure & 5.8 & 4.1 & 0.51 & $1.2(0.4,3.8)$ & 0.72 \\
Psychosis & 3.5 & 0.5 & 0.04 & $9.5(0.9,98.5)$ & 0.06 \\
Hematologic & 64.0 & 58.1 & 0.35 & $1.2(0.7,2.0)$ & 0.49 \\
Leukopenia & 40.7 & 35.1 & 0.36 & $1.2(0.7,2.0)$ & 0.48 \\
Lymphopenia & 38.4 & 36.5 & 0.76 & $1.1(0.7,1.8)$ & 0.73 \\
Thrombocytopenia & 15.1 & 12.2 & 0.49 & $1.1(0.5,2.2)$ & 0.86 \\
Anti-dsDNA & 77.9 & 47.8 & $<0.01$ & $3.4(1.9,6.1)$ & $<\mathbf{0 . 0 1}$ \\
Anti-Smith & 33.7 & 14.4 & $<0.01$ & $2.8(1.5,5.0)$ & $\mathbf{0 . 0 1}$ \\
Antiphospholipid & 57.0 & 54.5 & 0.70 & $1.1(0.7,1.8)$ & 0.70 \\
\hline & & &
\end{tabular}


Table 3

Association with Renal involvement: Percentage of Patients with SLE Serologies among those with and without ACR Lupus Nephritis

\begin{tabular}{lllllr}
\hline Variable & Renal involvement $(\boldsymbol{\%})$ & $\begin{array}{l}\text { No Renal involvement } \\
(\boldsymbol{\%})\end{array}$ & p-value & Odds Ratio (95\% CI) & $\begin{array}{r}\text { Adjusted p-value for Age } \\
\text { and Ethnicity }\end{array}$ \\
\hline Anti-C1q & 45.5 & 19.3 & $<0.01$ & $3.2(1.8,5.6)$ & $<\mathbf{0 . 0 1}$ \\
Anti-dsDNA & 80.2 & 44.4 & $<0.01$ & $4.7(2.5,8.6)$ & $<\mathbf{0 . 0 1}$ \\
Anti-Smith & 29.7 & 15.0 & $<0.01$ & $1.9(1.1,3.6)$ & $\mathbf{0 . 0 3}$ \\
Low complement & 78.2 & 50.2 & $<0.01$ & $2.8(1.5,4.9)$ & $<\mathbf{0 . 0 1}$ \\
\hline
\end{tabular}




\section{Table 4}

Odds ratios (OR) of SLICC renal involvement ${ }^{a}$ in patients with SLE $(\mathrm{N}=308)$ by individual antibody status, adjusted for demographic and serologic characteristics

\begin{tabular}{lccr}
\hline Covariates & SLICC renal (OR) & $\mathbf{9 5 \%}$ CI & p-value \\
\hline Age (years) & & & \\
$\quad 30$ (ref.) & & & \\
$>30$ & 1.00 & & \\
Ethnicity & 0.44 & $0.25-0.78$ & $<\mathbf{0 . 0 1}$ \\
$\quad$ African American (ref.) & 1.00 & & \\
$\quad$ White & 0.28 & $0.14-0.60$ & $<\mathbf{0 . 0 1}$ \\
Asian & 0.42 & $0.16-1.08$ & 0.07 \\
Hispanic/Latino & 0.40 & $0.09-1.71$ & 0.22 \\
Gender & & & \\
$\quad$ Male (ref.) & 1.00 & & \\
Female & 0.46 & $0.19-1.14$ & 0.09 \\
ANA & 0.22 & $0.05-1.01$ & 0.05 \\
Anti-dsDNA & 4.05 & $2.10-7.90$ & $<\mathbf{0 . 0 1}$ \\
Low Complement & 1.87 & $0.98-3.59$ & $\mathbf{0 . 0 6}$ \\
Anti-Clq & 2.30 & $1.26-4.19$ & $<\mathbf{0 . 0 1}$ \\
\hline
\end{tabular}

${ }^{a}$ SLICC renal involvement is defined as urine protein-to-creatinine ratio (or 24-hour urine protein) representing 500mg/24 hours or red blood cell casts; estimates from multivariable logistic regression model, constant term 3.44, 95\% CI $0.51-23.07$, p-value 0.2 )

$b_{\text {ref. denotes the reference group for each category }}$ 


\section{Table 5}

Odds ratios (OR) of SLICC renal involvement ${ }^{a}$ in patients with SLE (N=308) by antibody patterns, adjusted for demographics (age, ethnicity and gender)

\begin{tabular}{|c|c|c|c|c|c|c|}
\hline \multicolumn{3}{|c|}{ Serologic patterns } & \multirow[t]{2}{*}{ N (308) } & \multirow[t]{2}{*}{ SLICC renal (OR*) } & \multirow[t]{2}{*}{ 95\% CI } & \multirow[t]{2}{*}{ p-value } \\
\hline Anti-C1q & Anti-dsDNA & Low Complement & & & & \\
\hline Negative (ref.) $b$ & Negative & Negative & 75 & 1.00 & & \\
\hline Negative & Negative & Positive & 41 & 1.83 & $0.62-5.34$ & 0.27 \\
\hline Negative & Positive & Negative & 35 & 2.46 & $0.79-7.61$ & 0.12 \\
\hline Negative & Positive & Positive & 71 & 5.23 & $2.10-13.05$ & $<0.01$ \\
\hline Positive & Negative & Negative & 6 & 4.06 & $0.60-27.30$ & 0.15 \\
\hline Positive & Negative & Positive & 13 & 0.66 & $0.07-6.11$ & 0.72 \\
\hline Positive & Positive & Negative & 9 & 5.74 & $1.16-28.29$ & 0.03 \\
\hline Positive & Positive & Positive & 58 & 14.89 & $5.77-38.44$ & $<0.01$ \\
\hline
\end{tabular}

${ }^{a}$ SLICC renal involvement is defined as urine protein-to-creatinine ratio (or 24-hour urine protein) representing $500 \mathrm{mg} / 24$ hours or red blood cell casts; estimates of odds ratios (OR) are from multivariable logistic regression model, constant term 0.95 , $95 \%$ CI 0.26 - 3.49, p-value 0.94 )

$b_{\text {ref. denotes the reference group for each category }}$ 